파종방법에 따른 수크령, 갈대, 억새의 발아 및 초기생장 특성*

\author{
조용현 ${ }^{1)} \cdot$ 이가형 ${ }^{2)}$ \\ 1) 공주대학교 조경학과 ${ }^{2)}$ 공주대학교 조경학과 대학원

\section{Germination and Early Growth Characteristics of Pennisetum alopecuroides, Phragmites communis, and Miscanthus sinensis According to the Seeding Methods*}

\author{
Cho, Yong-Hyeon ${ }^{1)}$ and Lee, Ka-hyung ${ }^{2)}$ \\ ${ }^{1)}$ Dept. of Landscape Architecture, Kongju National University, \\ ${ }^{2)}$ Dept. of Landscape Architecture, Graduate school of Kongju National University.
}

\begin{abstract}
To investigate the possibility of developing the seeding measure for river bank slope revegetation, germination experiment and early growth observation were conducted using 3 native species growing naturally around river banks such as Pennisetum alopecuroides, Phragmites communis, and Miscanthus sinensis. The applied seeding methods were 3 such as scattering seeds, tillage after scattering seeds, and covering up seed with soil after scattering seeds. According to seeding methods, germination experiment and early growth observation were carried out on nursery bed soil in greenhouse. As results of this study, all the 3 native plant species' germination ratio and growth in length on nursery bed soil were highest on the seeding method of covering up seed with soil. Also it was verified by Duncan's multiple range test that the germination ratio and growth in length on the seeding method
\end{abstract}

* 본 연구는 환경부 “차세대 핵심환경기술개발사업”으로부터 지원을 받았습니다.

First author : Cho, Yong-Hyeon, Dept. of Landscape Architecture, Kongju National University, 54 Daehak-ro Yesan-eup Yesan-gun Chungnam-do 340-702, Republic of Korea, Tel : +82-41-330-1446, E-mail : yhcho@kongju.ac.kr

Corresponding author : Cho, Yong-Hyeon, Dept. of Landscape Architecture, Kongju National University, 54 Daehak-ro Yesan-eup Yesan-gun Chungnam-do 340-702, Republic of Korea, Tel : +82-41-330-1446, E-mail : yhcho@ kongju.ac.kr

Received : 22 January, 2014. Revised : 1 February, 2014. Accepted : 18 February, 2014. 
of covering up seed with soil is distinguished from those on other two seeding methods. According to this results, the best possible seeding measure to be developed should be mechanical seed spraying with soil.

Key Words : Revegetation, River bank plant, Growth in length, Nursery bed soil.

\section{I. 서 론}

하천은 지역 생태계를 연결해주며 어디에서 나 친근하게 볼 수 있는 생태권역이다. 또한 이 수 - 치수기능뿐만 아니라 가장 다양성이 풍부한 생태계의 보고로서 동 - 식물의 서식처 기능, 심 미적 기능 등의 환경기능이 있다(Kim 등, 2006). 하지만 급속한 경제발전과 산업화와 함께 지역 민에게 집약적으로 이용되어온 하천은 간섭과 교란으로 인해 하천의 생태적인 기능이 크게 훼 손되었다.

선진국에서는 인공적이고 획일적인 하천정 비로 인한 문제점들이 나타나면서 인공화된 하 천을 자연형 하천으로 복원하고자 사회적·기 술적 대안들이 다방면으로 모색되고 있으며, 일부 선진국에서는 이미 하천의 생태적 복원운 동과 복원기법이 전국적으로 시행되고 있는데, 스위스의 하천 '재생(Wiederbelebung)', 독일의 하천 '재자연화(Renaturierung der Gewasser)', 일본의 '다자연형 하천(多自然型 河川) 가꾸 기' 등이 그 예이다(Cho, 1997).

국내에서는 1970년대 초 하천법을 제정하고 몇 차례의 개정을 거치면서 본격적으로 하천을 관리하기 시작하였지만, 하천법에 의한 하천정 비의 주된 목적은 국가적인 차원에서 홍수로 인한 재해방지와 용수공급을 위한 것이었다 (Cho, 1997). 이러한 치수와 이수의 목적으로 정비된 하도는 직선화되었으며, 하폭을 넓히고 제방 및 호안은 콘크리트 블록이나 돌망태 등 으로 시공되면서 생태적 - 경관적 측면에서 부
적합한 결과를 나타냈다.

하천의 제방은 홍수를 예방하기 위해 만든 중요한 치수안전 시설물(Kim, 2008)로서 제방 사면 보호를 위해 콘크리트 블록이나 돌망태 등을 주로 사용했다. 이러한 제방공사는 하천 의 대규모 획일화를 야기해 생태계를 교란시키 는 야생식물이 급속히 번지는 결과를 가져왔다. 이러한 생태계 교란 야생식물은 번식력이 강한 외래종으로 자연생태계에 유입되면서 토종 서 식지를 잠식하여 생태계의 균형을 깨고 종의 다양성을 떨어뜨리며, 자연스럽지 않은 경관을 연출하게 된다. 이에 치수안전에 지장이 없는 범위에서는 하천의 식생을 고려하고 빠른 피복 과 제방 안정화에 기여하는 종을 선정하고 시 공해야 한다. 그러나 현재 급속녹화에 치중해 외래종 또는 수입 종자가 활용되고 있다. 녹화 에 사용되는 자생종 식재 공법의 경우 값비싼 포트식재가 주를 이루고, 효율적인 토착종 파 종공법은 거의 없는 실정이며 연구도 미흡하여 파종 식재공법과 생육특성에 관한 기초연구가 절실히 요구되고 있다.

현재 생태하천 복원이나 복원을 위한 녹화사 업에서 자생종을 이용한 식물의 도입은 굉장히 중요한 비중을 차지한다. 이러한 관심으로 생 태복원의 중요성이 인식되고 요구되면서 하천 의 각종 식물 종자의 발아 개선과 식재에 관한 연구가 증대되고 있다.

종자의 발아 특성과 파종에 관한 연구를 살 펴보면 Yun(2001)의 온도에 따른 녹화용 식물 의 발아율, Jung(2004)의 녹화용 자생 화본과 
식물개발을 위한 자생지 및 발아특성에 관한 연구, Lee(2013)의 비탈면 녹화용 자생식물의 종자 채취시기에 따른 발아특성, $\operatorname{Kim}(2000)$ 의 갈대와 애기부들의 종자발아 및 실생의 생장, Shin(2011)의 자연형 하천 공법의 적용에 따른 식생 피복에 관한 연구, Choi와 Kim(1999)의 자연형 하천 식생복원을 위한 달뿌리풀, 물억 새, 솔새, 수크령의 녹화방법에 관한 연구, $\mathrm{Lim}$ 등(2010)의 식물, 산림; 채종시기 및 $\mathrm{GA}_{3}$ 처리 가 적수크령 종자의 발아율 향상에 미치는 영 향, $\operatorname{Kim}(2013)$ 의 화본과 경관식물 3 종의 발아, 육묘 특성과 경관성 평가, Choi(2011)의 수생태 계 복원을 위한 수생식물의 기반환경에 따른 생육특성 및 식재모델 개발, Jung(2000)의 수변 녹화를 위한 갈대속과 억새속 식물의 뗏장형성 및 식생공법에 관한 연구 등이 있다.

연구 동향을 파악해본 결과 대부분의 연구가 하천 식생 종자의 발아율을 개선하고 발아특성 을 밝히는 것이 주를 이룬다. 또한 종의 다양성 이 적고 실험실내 Incubator에서만 이루어진 실 험이 대부분이어서 노지의 포장이나 상토에서 의 발아율이나 초기 생육특성을 실험한 연구는 미흡하다.

따라서 본 연구의 목적은 효율적인 토착종을 이용한 파종 식재 공법 개발에 앞서, 우선적으 로 활용성이 높은 토착종 초본 종자를 선발하 여 상토에서의 발아실험을 통해 발아특성을 파 악하고, 초기 생장특성을 밝혀 자생종을 이용 한 녹화공법 개발에 필요한 기초자료를 제공하 는 데에 있다.

\section{II. 재료 및 방법}

\section{1. 공시재료}

본 연구에서는 하천의 제방, 제방사면, 고수 부지에 형성되는 하천변 식물 중 종자채취가 용이하고, 도로건설로 인한 비탈면과 각종 훼 손 비탈면 녹화에 많이 사용되고 있으며, 자연 하천 수변의 주요 식생으로서 $8.2 \%$ 를 차지하는 (환경부, 2006) 벼과 식물중 다년초인 수크령 (Pennisetum alopecuroides (L.) Spreng.), 갈대 (Phragmites communis Trin.), 억새(Miscanthus sinensis Andersson)를 공시식물로 선정하였다. 공 시 종자는 2012년 10월 11월 동안에 충남 예산 군을 중심으로 무한천과 신양천 유역에서 채취하 였다. 채종 후 그늘에서 5 일 이상 자연건조 후 밀 폐용기에 넣어 $5^{\circ} \mathrm{C}$ 의 냉장고에 보관하면서 사용 하였다.

하천에서 채취한 공시종자의 크기, 무게를 알아보기 위하여 자연건조 후 손으로 종피를 제거하고 무작위로 100 립의 종자를 선별하여 버니어캘리퍼스로 크기를 측정하였고, 무게는 1000 립을 전자저울(TD200. OHAUS)을 이용하 여 측정하였다. 크기와 무게는 식물종별로 3 회 실시하여 평균을 조사하였다. 본 연구에서 사 용된 종자의 길이와 폭, 1000 립중, 형상과 채종 시기를 정리하면 Table 1과 같다.

\section{2. 실험방법}

1) Incubator 실험

상토 발아실험을 진행하기에 앞서 종자의 휴

Table 1. Characteristics of experimental seeds.

\begin{tabular}{lcccc}
\hline \multicolumn{1}{c}{ Scientific name } & $\begin{array}{c}\text { Length } \\
(\mathrm{mm})\end{array}$ & $\begin{array}{c}\text { Width } \\
(\mathrm{mm})\end{array}$ & $\begin{array}{c}\text { weigt of } 1000 \\
\text { seeds }(\mathrm{g})\end{array}$ & $\begin{array}{c}\text { Seed-gathering } \\
\text { Time }\end{array}$ \\
\hline Pennisetum alopecuroides (L.) Spreng. & 2.5 & 1.1 & 4.8 & 2012.10 .20 \\
\hline Phragmites communis Trin. & 1.8 & 0.7 & 1.8 & 2012. 11. 10 \\
\hline Miscanthus sinensis Andersson & 2.7 & 1.0 & 2.3 & 2012. 10. 20 \\
\hline
\end{tabular}


면 유- 무와 종자의 발아율을 확인하고자 별도 의 처리 없이 예비발아실험을 실시하였다. 예 비발아실험에 사용된 종자는 채종 후 건조하여 정선 후 직경 $9 \mathrm{~cm}$ 의 Petri dish에 여과지 2매를 깔고 마르지 않도록 수시로 증류수를 공급한 후 종자 100 립을 완전임의배치하고 3 반복으로 실시하였다. 10 일 동안 실험에 사용된 Incubator 의 조건은 온도 $25^{\circ} \mathrm{C}$ 항온조건, 16 시간 $\cdot 8$ 시간 의 광 - 암주기 조건으로 실시하였다.

\section{2) 상토 발아실험}

실험은 공주대학교 산업과학대학 내 실험장 에서 실시하였고, 실험장에는 실험을 위한 온 상이 설치되어 있다. 온상의 면적은 $5 \mathrm{~m} \times 10 \mathrm{~m}$ 이 며, 기존 비닐하우스와 차이는 없다. 온상 내에 자기온습도기록계(SATO)를 배치하여 실험기간 동안 온도와 습도를 측정하였다. 실험용 pot의 크기는 직경 $19 \mathrm{~cm}$, 높이 $23 \mathrm{~cm}$, 표면적 $283.4 \mathrm{~cm}^{2}$ 이다. 토양은 판매용 상토(흥농바이오상토)를 사용하였다. 실험용 종자로는 손을 이용하여 직접 선별하는 입선법으로 발아율이 높고 발아 세가 왕성한 우량종자를 선별하여 사용하였다.

전처리의 경우 수크령은 $5^{\circ} \mathrm{C}$ 에서 24 시간 저 온처리하였으며, 억새와 갈대는 종자가 휴면하 지 않아 아무 처리도 하지 않았다. 파종방법은 종자 흩뿌리기, 종자 흩뿌리기 후 경운(이하 '경운법'으로 약칭함), 종자 흩뿌리기 후 복토 (이하 '복토법'로 약칭함)의 세 가지로 구분하 였다. 복토법의 경우 각 실험구별로 각각 $200 \mathrm{cc}$ 의 상토를 복토재로 하여 종자 흩뿌리기 후 복 토하였고, 멀칭은 하지 않았다. 파종량은 한 개 pot에 종자 100 립씩 파종하였고, 실험구의 배치 는 완전 임의배치법으로 파종방법당 6반복 실 시하였다. 관수는 충분한 수분을 공급하기 위 하여 실험기간동안 24 시간 간격으로 조리개를 사용하여 1 회 $1500 \mathrm{cc}$ 씩 계량하여 공급하였으 며, 토양건조가 심한 경우에는 1 일 2회로 관수 횟수를 늘렸다.
발아율 조사는 유근이 $2 \mathrm{~mm}$ 이상 자란 것을 발아종자로 판정하였으며, 발아가 멈추는 시점 까지 조사하였다. 분석은 통계 프로그램 SPSS 18.0 을 이용하여 식물종별로 발아율을 Duncan's 의 다중검정법으로 비교 분석하였다.

수크령의 상토 발아실험 기간 동안 관측된 평균온도는 $35.7^{\circ} \mathrm{C}$ 이고 평균습도는 $51.2 \%$ 였다. 온 - 습도의 측정 시간은 오후 2시이며 24시간 간격으로 측정하였다. 실험 장소가 온상이었으 며 6 8월에 거쳐 실험을 진행하였기 때문에 이와 같은 값을 나타냈다.

한편 수크령 실험 1 개월 후 시작된 갈대와

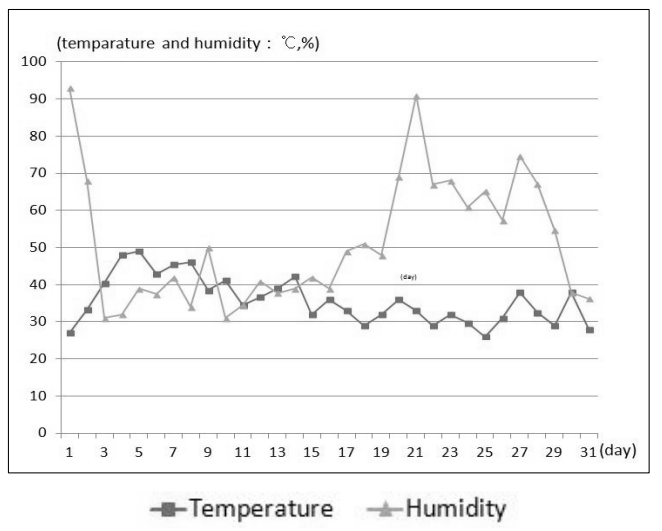

Figure 1. Temperature and humidity during germination of Pennisetum alopecuroides and Miscanthus sinensis.

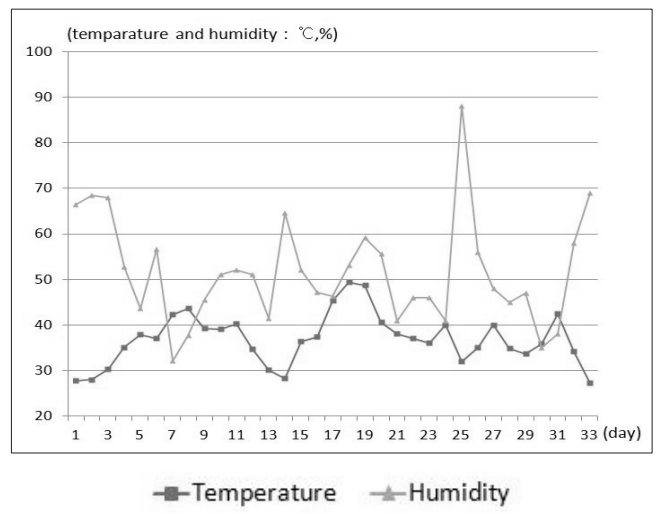

Figure 2. Temperature and humidity during germination of Phragmites communis. 
억새의 상토 발아실험 기간 동안 평균온도는 $36.8^{\circ} \mathrm{C}$ 이고 평균습도는 $51.5 \%$ 였다.

\section{3) 상토 생육실험}

상토 생육실험은 상토 발아실험의 연속으로 온상에서 실시하였으며, 파종방법당 6반복으로 이루어진 실험구 식물의 생장량을 측정하였다. 측정 도구로는 버니어캘리퍼스를 사용하였다. 측정 방법은 모든 식물의 초장을 측정하여 평 균을 평균생장길이로 파악하였고, 3 일 간격으 로 약 8 주 동안 초장을 측정하였다. 분석은 실 험기간의 중간의 생장 값과 실험기간의 마지막 날 생장 값의 유의성을 알아보기 위하여 식물 종별로 Duncan's의 다중검정법으로 비교 분석 하였다.

\section{III. 결과 및 고찰}

\section{Incubator 실험 결과}

별도의 처리 없이 $25^{\circ} \mathrm{C}$ 항온조건에서 발아 실험을 진행한 결과 세 종 모두 3 일 만에 발아 가 시작되었고, 수크령, 갈대, 억새의 평균 발아 율은 각각 $88.6 \%, 74.2 \%, 66.7 \%$ 로서 차이는 있지만 모두 양호한 발아율을 보여 휴면하지 않는 것으로 나타났다. 이러한 특성으로 볼 때 자생지에서 채종 후 별도의 처리를 하지 않아 도 높은 발아율을 나타낼 것으로 판단되었다.

\section{2. 수크령}

수크령은 파종 후 4 일 만에 발아가 시작되었 으며, 발아가 멈추는 시점까지는 28 일이 걸렸다. 세 가지 파종방법 중 복토가 우세한 발아율을 나 타냈으며, 발아가 시작된 시점에서 7일 이후까 지 발아율이 급속도로 올라갔으나 이후 서서히 정체되었다. 그러나 종자 흩뿌리기의 경우 초기 종자발아에서부터 발아가 멈추는 시점까지 꾸준 한 발아율을 나타냈다(Figure 3 참조). 최종 발아 율은 종자 흩뿌리기는 $74.0 \%$, 경운법은 $76.2 \%$,
복토법은 92.8\%로 집계되었다(Table 2 참조).

Duncan's의 다중검정법에 의한 유의성을 살 펴보면, 종자 흩뿌리기와 경운법은 유의한 차 이가 없으며, 복토법과는 유의한 차이가 있는 것으로 나타났다(Table 2 참조).

평균생장 길이는 발아가 시작한 시점에서부 터 측정하였는데 약 30 일 동안 급격히 성장하였 으나 그 이후부터는 서서히 정체됨을 나타냈다. 생육실험을 시작하고 열흘 동안은 비슷한 생장 량을 나타냈고 30 일 이후에는 복토법의 실험구 가 다른 파종방법에 의한 실험구보다 생장량이 높게 나타났다(Figure 4 참조). 실험시작 후 25 일째 되는 날의 생장량 값은 종자 흩뿌리기는 $256.8 \mathrm{~mm}$ 이고, 경운법은 $304.5 \mathrm{~mm}$, 복토법은 $319.7 \mathrm{~mm}$ 였다. 한편, 52 일째 되는 날의 생장량 값 은 종자 흩뿌리기는 $722.3 \mathrm{~mm}$, 경운법은 $712.0 \mathrm{~mm}$, 복토법은 $754.0 \mathrm{~mm}$ 였다(Table 3 참조).

실험시작 후 25 일과 52 일의 생장량 값을

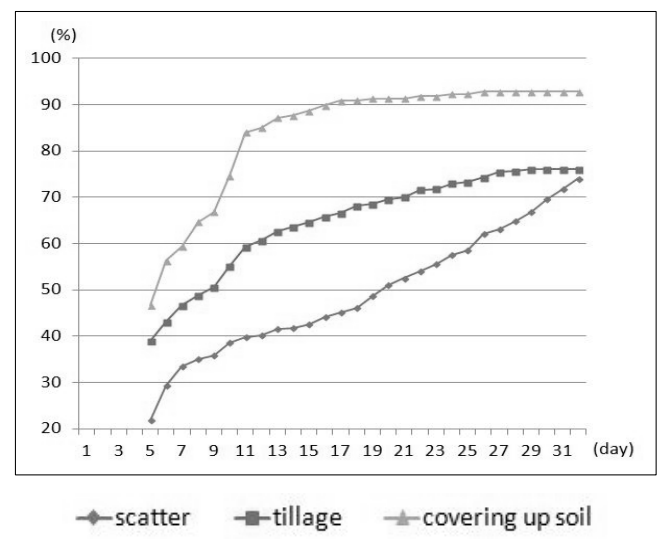

Figure 3. Germination of Pennisetum alopecuroides.

Table 2. Germination of Pennisetum alopecuroides.

\begin{tabular}{l|c}
\hline \hline \multicolumn{1}{c|}{ Seeding method } & Germination rate(\%) \\
\hline Scattering seeds & $74.0 \pm 14.7 \mathrm{a}$ \\
\hline Tillage after scattering seeds & $76.2 \pm 11.6 \mathrm{a}$ \\
\hline $\begin{array}{l}\text { Covering up seed with soil after } \\
\text { scattering seeds }\end{array}$ & $92.8 \pm 3.4 \mathrm{~b}$ \\
\hline
\end{tabular}


Duncan's의 다중검정법으로 분석하였다. 25 일 째 생장량은 경운법과 복토법 사이에 유의한 차이가 없으나 종자 흩뿌리기와는 각각 유의한 차이가 있는 것으로 나타났다. 52 일째 생장량 은 종자 흩뿌리기와 경운법 사이에는 유의한 차이가 없으나, 복토법과는 각각 유의한 차이 가 있었다(Table 3 참조).

\section{3. 갈대}

갈대 상토 발아실험에서는 파종 후 6일 만에 발아가 시작되었으며, 발아가 멈추는 시점까지 는 33 일이 걸렸다. 갈대 발아가 시작된 시점에 서 10 일 동안 비슷한 발아율을 나타냈고, 그 이 후에 높은 발아율을 보였다(Figure 5 참조). 최 종 발아율은 종자 흩뿌리기는 $51.8 \%$, 경운법은 $62.7 \%$, 복토법은 $71.5 \%$ 로 집계되었다(Table 4 참조)

Duncan's의 다중검정법에 의한 유의성을 살 펴보면, 세 가지 파종방법 모두 서로 간에 유의 한 차이가 있었다(Table 4 참조).

본 연구에서의 평균생장 길이는 발아가 시작 한 시점에서부터 측정하였는데, 약 40 일 동안 급 격히 성장하였으나 그 이후부터는 서서히 정체 됨을 나타냈다. 파종방법별로는 생육실험을 시 작하고 약 12 일 동안 비슷한 생장량을 나타냈고, 이후에는 복토법이 일정하게 증가했으며, 종자 흩뿌리기와 경운법의 실험구에서는 약간 정체 됨을 보였다. 마지막 관찰에서는 세 가지 파종방 법별 생장은 크게 차이나지 않았다(Figure 6 참 조). 실험시작 후 25 일의 생장량 값은 종자 흩뿌 리기는 $219.7 \mathrm{~mm}$, 경운법은 $216.2 \mathrm{~mm}$, 복토법은 $254.0 \mathrm{~mm}$ 였다. 실험시작 후 52 일의 생장량 값을 분석해보면 종자 흩뿌리기는 $617.3 \mathrm{~mm}$, 경운법 은 $605.0 \mathrm{~mm}$, 복토법은 $627.0 \mathrm{~mm}$ 를 나타냈다 (Table 5 참조)

실험시작 후 25 일과 52 일의 생장량 값을 Duncan's의 다중검정법으로 분석하였다. 25 일 자료에 따르면 종자 흩뿌리기와 경운법 사이에

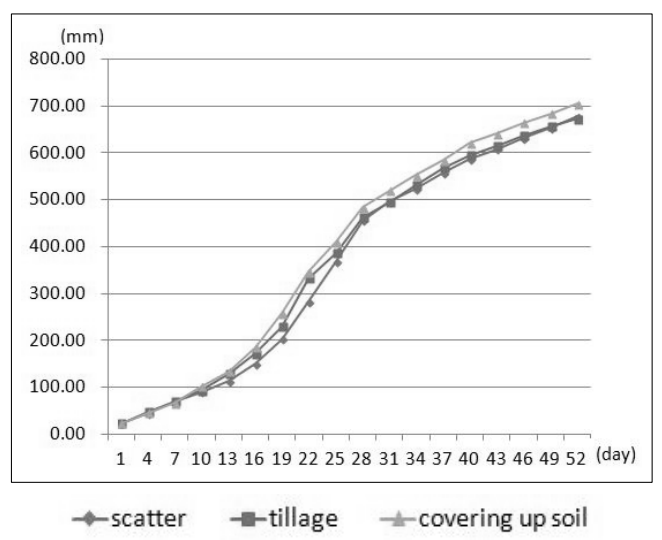

Figure 4. Growth in length of Pennisetum alopecuroides.

Table 3. Growth in length of Pennisetum alopecuroides.

\begin{tabular}{l|c|c}
\hline \hline \multicolumn{1}{c|}{ Seeding method } & 25th day & 52th day \\
\hline Scattering seeds & $256.8 \pm 39.7 \mathrm{a}$ & $722.3 \pm 17.1 \mathrm{a}$ \\
\hline $\begin{array}{l}\text { Tillage after scattering } \\
\text { seeds }\end{array}$ & $304.5 \pm 31.6 \mathrm{~b}$ & $712.0 \pm 25.6 \mathrm{a}$ \\
\hline $\begin{array}{l}\text { Covering up seed with } \\
\text { soil after scattering seeds }\end{array}$ & $319.7 \pm 24.0 \mathrm{~b}$ & $754.0 \pm 16.4 \mathrm{~b}$ \\
\hline
\end{tabular}

*Duncan's multiple range test.

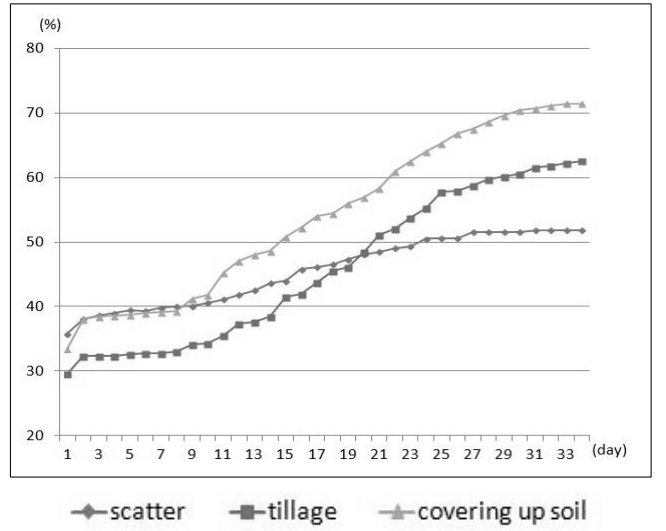

Figure 5. Germination of Phragmites communis.

Table 4. Germination of Phragmites communis.

\begin{tabular}{l|c}
\hline \hline \multicolumn{1}{c|}{ Seeding method } & Germination rate(\%) \\
\hline Scattering seeds & $51.8 \pm 4.5 \mathrm{a}$ \\
\hline $\begin{array}{l}\text { Tillage after scattering seeds } \\
\text { Covering up seed with soil after } \\
\text { scattering seeds }\end{array}$ & $62.7 \pm 5.6 \mathrm{~b}$ \\
\hline
\end{tabular}

*Duncan's multiple range test. 
는 유의한 차이가 없었지만, 복토법은 다른 방법 과 유의한 차이가 있는 것으로 나타났다. 52일 자료에 따르면 경운법과 복토법 사이에 유의한 차이가 있는 것으로 나타났다(Table 5 참조).

\section{4. 억새}

억새 상토 발아실험에서는 6 일 만에 발아가 시작되었으며 최종발아까지는 33 일이 걸렸다 (Figure 7 참조). 최종 발아율은 종자 흩뿌리기 $50.2 \%$, 경운법 $54.2 \%$, 복토법 $66.0 \%$ 로 집계되 었다(Table 6 참조). 수크령이나 갈대에 비해 낮은 발아율을 나타냈다.

Duncan's의 다중검정법에 의한 유의성을 살 펴보면, 종자 흩뿌리기와 경운법은 유의한 차 이가 없고, 복토법과는 유의한 차이가 있는 것 으로 나타났다(Table 6 참조).

본 연구에서 평균생장 길이는 발아가 시작된 시점부터 약 40 일 동안 꾸준히 성장하였고 그 이후 정체되었다. 복토법과 경운법은 약 31 일 동 안 비슷한 생장량을 나타냈고, 그 이후에 복토법 이 높은 생장량을 나타냈다. 반면 종자 흩뿌리기 의 실험구는 일정한 생장량을 나타냈다(Figure 8 참조). 실험시작 후 25 일의 생장량 값은 종자 흩 뿌리기는 $114.5 \mathrm{~mm}$, 경운법은 $78.8 \mathrm{~mm}$, 복토법 은 $80.7 \mathrm{~mm}$ 를 나타냈다. 52 일 생장량 값은 종자 흩뿌리기 $309.5 \mathrm{~mm}$, 경운법 $298.2 \mathrm{~mm}$, 복토법 $343.8 \mathrm{~mm}$ 를 나타냈다(Table 7 참조).

실험시작 후 25 일과 52 일의 생장량 값을 Duncan's의 다중검정법으로 분석하였다. 25 일 자료와 52일 자료에서 공통적으로 종자 흩뿌리 기와 경운법과는 유의한 차이가 없으나, 복토 법과 다른 파종방법 사이에는 유의한 차이가 있는 것으로 나타났다(Table 7 참조).

\section{5. 고찰}

수크령과 갈대, 억새의 종자로 인큐베이터에서 발아실험을 한 결과 타 연구에서와 마찬가지로 종 자가 휴면하지 않고 발아율이 높았으며, 비교적

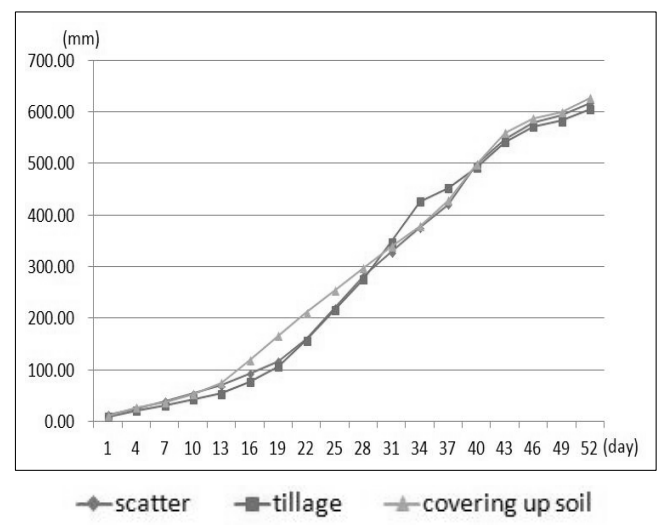

Figure 6. Growth in length of Phragmites communis.

Table 5. Growth in length of Phragmites communis.

\begin{tabular}{l|c|c}
\hline \hline \multicolumn{1}{c|}{ Seeding method } & 25 th day & 52 th day \\
\hline Scattering seeds & $219.7 \pm 10.6 \mathrm{a}$ & $617.3 \pm 22.1 \mathrm{ab}$ \\
\hline $\begin{array}{l}\text { Tillage after scattering } \\
\text { seeds }\end{array}$ & $216.2 \pm 17.7 \mathrm{a}$ & $605.0 \pm 7.6 \mathrm{a}$ \\
\hline $\begin{array}{l}\text { Covering up seed with } \\
\text { soil after scattering seeds }\end{array}$ & $254.0 \pm 29.2 \mathrm{~b}$ & $627.0 \pm 15.8 \mathrm{~b}$ \\
\hline
\end{tabular}

* Duncan's multiple range test.

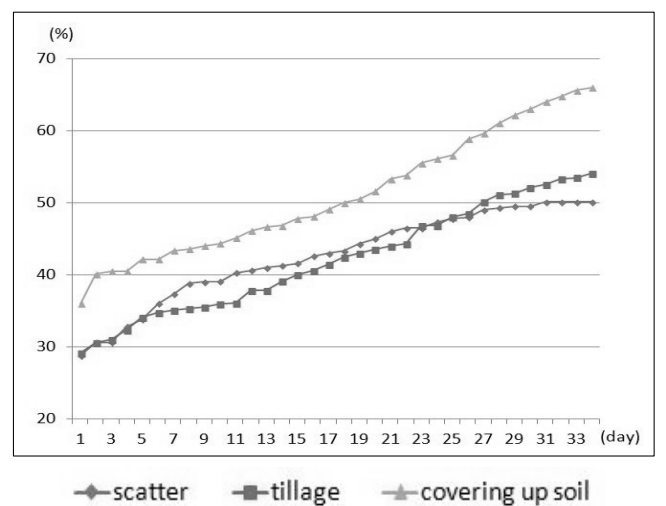

Figure 7. Germination of Miscanthus sinensis.

Table 6. Germination of Miscanthus sinensis.

\begin{tabular}{l|c}
\hline \hline \multicolumn{1}{c|}{ Seeding method } & Germination rate(\%) \\
\hline Scattering seeds & $50.2 \pm 1.7 \mathrm{a}$ \\
\hline Tillage after scattering seeds & $54.2 \pm 4.3 \mathrm{a}$ \\
\hline $\begin{array}{l}\text { Covering up seed with soil after } \\
\text { scattering seeds }\end{array}$ & $66.0 \pm 1.4 \mathrm{~b}$ \\
\hline
\end{tabular}

* Duncan's multiple range test. 


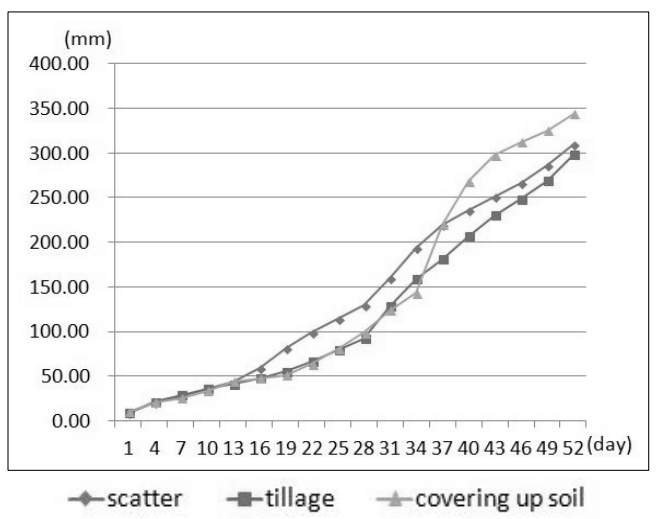

Figure 8. Growth in length of Miscanthus sinensis.

Table 7. Growth in length of Miscanthus sinensis.

\begin{tabular}{l|c|c}
\hline \hline \multicolumn{1}{c|}{ Seeding method } & 25 th day & 52 th day \\
\hline Scattering seeds & $114.5 \pm 25.8$ a & $309.5 \pm 36.5 \mathrm{a}$ \\
\hline $\begin{array}{l}\text { Tillage after scattering } \\
\text { seeds }\end{array}$ & $78.8 \pm 22.8$ a & $298.2 \pm 29.8 \mathrm{a}$ \\
\hline $\begin{array}{l}\text { Covering up seed with } \\
\text { soil after scattering seeds }\end{array}$ & $80.7 \pm 21.7 \mathrm{~b}$ & $343.8 \pm 34.4 \mathrm{~b}$ \\
\hline * Duncan's multiple range test
\end{tabular}

발아하기까지 짧은 일수를 나타냈다. 발아율과 생 리특성을 통해 별도의 처리 없이 자생지에서 채종 한 종자의 활용 가능성이 높다고 판단된다.

공시식물의 종자를 채취하여 직접 실험을 해 본 결과에 따르면 채취 시기와 지역마다 종자의 양과 성숙도가 차이가 있어 발아특성과 생장에 영향을 미쳐 상이한 값을 나타내기도 한다. 이 는 재배종이 아닌 야생종이고 환경의 변수에 의해 성숙도와 충실도가 균일한 종자를 채취하 기에 많은 제약이 수반되기 때문이다. 현재 국 내 자생식물 생산은 재배면적 $300 \mathrm{ha}$, 연간 생산 액 1,000 억 원 정도로 추정된다. 그러나 대부분 의 자생식물들은 주로 관상용으로 이용되고, 절개지나 하천제방 사면의 지지력 강화를 위한 식물들의 종자 확보와 재배는 이루어지지 않고 있다. 자생종자가 수입종자에 비해 가격 경쟁 력이 낮지만 이대로 방관만 할 수는 없다. 국가 의 지원을 통해서라도 자생식물의 종자생산과
식물 생산을 위한 체계의 구축이 필요하다. 앞 으로 다양한 토착식물의 야생 종자를 공간과 지역의 특성에 따라 대량생산하는 연구가 필요 하며, 아울러 토착식물의 뿌리 생육 및 활착에 대한 연구도 진행되어야 할 것이다.

\section{IV. 결 론}

현재 급속녹화에 치중해 주로 외래종 또는 수입 종자가 활용되고 있고, 녹화에 사용되는 자생종 식재 공법의 경우 값 비싼 포트식재가 주를 이루고 있으며, 효율적인 토착종 파종공 법은 거의 없는 실정이다. 본 연구는 이러한 실 태를 개선하고자 하천 주변에서 흔하게 자생하 는 수크령, 갈대, 억새를 대상으로 상토에서의 종자의 발아와 생장 특성을 구명하기 위해 실 시되었다. 그 결과를 요약하면 다음과 같다.

첫째, 수크령의 경우 발아율은 종자 흩뿌리 기는 $74 \%$, 경운법 $76.1 \%$, 복토법은 $92.8 \%$ 로 복토법에서 가장 우세하였으며, 길이 생장도 복토법에서 가장 우수하였다. 다중검정법으로 분석한 결과 발아율에서는 종자 흩뿌리기와 경 운법 사이에는 유의한 차이가 없지만, 복토법 의 경우는 이들과 유의한 차이를 가지며, 길이 생장에서도 종자 흩뿌리기와 경운법 사이에 유 의한 차이가 없지만 복토법과는 유의한 차이를 가진다. 종합적으로 보면 복토법이 흩어뿌리기 와 경운법에 비해 높은 발아율을 나타냈다.

둘째, 갈대의 경우 발아율은 종자 흩뿌리기 $51.8 \%$, 경운법 $62.6 \%$, 복토법 $71.5 \%$ 로 복토법 이 가장 우세한 것으로 나타났으며, 길이 생장 역시 종자 흩뿌리기 후 복토에서 가장 우수하 였다. 다중검정법으로 분석한 결과 발아율에서 는 세 가지 파종방법 사이에는 모두 유의한 차 이가 있었고, 길이 생장에서는 복토법이 종자 흩뿌리기와는 유의한 차이가 없지만, 경운법과 는 유의한 차이가 있었다.

셋째, 억새의 경우 발아율은 종자 흩뿌리기 
$50.1 \%$, 경운법 $54.1 \%$, 복토법 $66 \%$ 로 복토법에 서 가장 우세하였다. 길이 생장에서는 중간 생 장과 최종 생장에서 결과가 다른데, 최종 생장 에서는 복토법에서 가장 우수하였지만, 중간 생장에서는 종자 흩뿌리기에서 가장 우수하였 고, 복토법에서는 중간이었다. 다중검정법으로 분석한 결과 상토 발아율은 종자 흩뿌리기와 경운법 사이에는 유의한 차이가 없으나 복토법 과는 모두 유의한 차이가 있는 것으로 밝혀졌 고, 길이 생장 또한 종자 흩뿌리기와 경운법 사 이에는 유의한 차이가 없지만, 복토법과는 모 두 유의한 차이가 있었다.

종합적으로 수크령, 갈대, 억새의 상토 발아 율은 세 가지 식물 모두 복토법에서 가장 우수 하였고, 최종적인 상토 길이 생장량 역시 모두 복토법에서 가장 우수하였다. 또한 그 차이가 다른 파종방법과 통계적으로 유의한 것으로 나 타나 종자와 토양의 혼합체를 이용한 취부공법 의 높은 실행 가능성을 확인할 수 있었다.

다만, 본 연구는 자연조건이 아닌 온실 안에 서 충분한 인공관수 조건하에서 이루어졌으므 로, 다양한 수분조건의 실험을 통해 제한요인 으로서 한계 수분조건의 규명이 필요하다. 또 한 복토공에 사용된 토양이 상토 하나에 한정 되었으므로, 향후 연구에서는 상토 이외의 실 용적인 토양혼합물을 활용한 취부공법 고안 및 적용 실험이 필요하다. 최종적으로는 공법 적 용 후에 자연적으로 유입되는 종과의 종간 경 쟁 특성을 규명하기 위한 노지포장 적용 후 모 니터링 연구도 필요할 것이다.

\section{인 용 문 헌}

Cho, Yong-Hyeon. 1997. Development of an Evaluation Method of Stream Naturalness for Ecological Restoration of Stream Corridors. a doctoral dissertation of Seoul National University's Graduate School.
Choi, B. S. 2011. Development of Planting Model and Growth Characteristics Depending on the Fundamental Environment of Hydrophites for Aquatic Ecosystem Restoration -Focusing on Phragmites communis-. a doctoral dissertation of Sangmyung University's Graduate School.

Choi, G. C. and Kim, N. C. 1999. Study on the Revegetation Methods of Phragmites japonica, Miscanthus sacchariflorus, Themeda triandra and pennisetum alopecuroides for the Rehabilitation of Close-to-Nature River. The Korea Society For Environmental Restoration And Revegetation Technology 2(2): 70-77.

Jung, D. Y. 2000. A Study on Sods Establishment and Planting Methods of Phramites spp. and Miscanthus spp. for Waterfront Vegetation. a doctoral dissertation of Chongju University's Graduate School.

Jung, Y. T. 2004. Study of habitat and germination characteristics of native Gramineae plants for revegetation. a master's thesis of Chungang University's Graduate School.

Kim, E. S. 2000. Germination and seeding growth of Phramites comminis and Typha- angustata. a master's thesis of Kongju National University's Graduate School of Education.

Kim, H. J. 2008. Near-to-nature River planning. Taerim. 122.

Kim, K. D. 2013. Germination, Plug Production and Visual Quality on Three Species of Ornamental Grasses. a master's thesis of Yonsei University's Graduate School.

Kim, S. G. $\cdot$ Kim, C $\cdot$ Chang, N. I. $\cdot$ Lee, S. H. and Choi, M. S. 2006. A Study on the Method of Evaluation of Nature-Friendly Stream Improvement Works. Korean Society of Civil Engineers 10: 1526.

Lee, J. Y. 2013. Germination Characteristics of 
Native Plant for slope Revegetation according to Colllection Time. a master's thesis of Kongju National University's Graduate School. Lim, C. S. · Oh, J. Y. · Seck, Y. C. and Kim, D. H. 2010. Articles: Plant \& Forest ; Effects of Harvest Time and GA3 Treatment on the Germination Rate of Pennisetum alopecuroides for. erythrochaetum. Journal of Agriculture \& Life Sciences. 44(6): 1-7.
Shin, C. H. 2011. A Study on the Vegetation Cover with Applying Close-to-Nature Stream Techniques -Focused on the Tan-Cheon Stream in Seongnam City-. a master's thesis of Kyungwon University's Graduate School.

Yun, J. S. 2001. Germination Rate of the Revegetation Plants according to Temperature. a master's thesis of Dankook University's Graduate School. 